\title{
PENGARUH PENERAPAN MODEL PEMBELAJARAN PROBLEM BASED LEARNING (PBL) TERHADAP KEMAMPUAN KOGNITIF MAHASISWA PADA MATA KULIAH PENGETAHUAN LINGKUNGAN
}

\author{
Ervina Mukharomah, Saleh Hidayat, Sapta Handaiyani, Ade Kartika \\ Program Studi Pendidikan Biologi, Fakultas Keguruan dan Ilmu Pendidikan \\ Universitas Muhammadiyah Palembang \\ Jl. Jendral Ahmad Yani 13 ulu Kota Palembang Indonesia \\ e-mail: mukharomah.ervina@gmail.com
}

\begin{abstract}
Abstrak
Penelitian yang berjudul Pengaruh Penerapan Model Pembelajaran Problem Based Learning (PBL) terhadap kemampuan kognitif Mahasiswa pada Mata Kuliah Pengetahuan Lingkungan. Adapun tujuan dari penelitian ini ialah untuk mengetahui pengaruh model pembelajaran PBL terhadap nilai kognitif mahasiswa di Prodi Biologi Universitas Muhammadiyah Palembang yang mengambil mata kuliah Pengetahuan Lingkungan. Penelitian ini telah dilaksanakan di FKIP Universitas Muhammadiyah Palembang pada mahasiswa semester VII (tujuh). Penelitian ini merupakan penelitian Eksperimental semu. Dengan menggunakan Kelas eksperimen kelas VII A yang berjumlah 44 orang mahasiswa dan kelas VII B berjumlah 35 orang mahasiswa diberikan perlakuan menggunakan Model PBL. Adapun data yang digunakan adalah data kuantitatif dari kedua kelas. Data kuantitatif dari kedua kelas diberikan PreetestPostest untuk mengetahui pengaruh Model Pembelajaran Problem Based learning terhadap kemampuan kognitif pada kedua kelas. Hasil penelitian dengan memberikan soal berjumlah 22 soal dengan tipe 10 Soal Pilihan Ganda, 5 Soal Menjodohkan, 5 Soal Sebab Akibat dan 2 Soal Essay. Dari hasil Pree-test nilai terendah 20 dan nilai tertinggi 76. Nilai Post-test nilai terendah adalah 66 dan tertinggi adalah 97. Sehingga dapat disimpulkan bahwa terdapat pengaruh yang sangat nyata di dalam penerapkan model pembelajaran PBL terhadap nilai kognitif mahasiswa yang dilihat dari nilai sebelum diberikan perlakuan dibandingkan nilai yang telah diberikan perlakuan. Hal ini dapat dilihat dari nilai Pre-test dan Post-test memiliki nilai signifiansi sebesar 0,530 artinya sig > dari 0,05
\end{abstract}

Kata Kunci: Problem Based Learning, Pengetahuan Lingkungan, Pre-test dan Post-test

\begin{abstract}
The research entitled The Effect of Application of Problem Based Learning (PBL) Learning Model on Students' Cognitive Ability in Environmental Knowledge Course. The purpose of this study was to determine the effect of the PBL learning model on the cognitive value of students in the Biology Study Program, Muhammadiyah University of Palembang who took the Environmental Knowledge course. This research has been carried out at FKIP Muhammadiyah University of Palembang in seventh (seven) semester students. This research is a quasi-experimental research. By using the experimental class VII A class which collected 44 students and class VII B opened 35 students were given treatment using the PBL model. The data used is quantitative data from the second class. Quantitative data from both classes were given Preetest-Posttest to determine the effect of Problem Based Learning Learning Model on cognitive abilities in both classes. The results of the research by providing 22 questions with the type of 10 Multiple Choice Questions, 5 Matching Questions, 5 Cause and Effect Questions and 2 Essay Questions. From the results of the Pree-test, the lowest score was 20 and the highest score was 76. The lowest score for the Post-test was 66 and the highest was 97. So it can be said that there is a very real influence in the application of the PBL learning model on the cognitive value of students as seen from the scores before being given. treatment compared to the value that has been given treatment. This can be seen from the Pre-test and Post-test values which have a significance value of 0.530, meaning sig > from 0.05 .
\end{abstract}

Keywords: Problem Based Learning, Environmental Knowledge, Pre-test and Post-test 


\section{PENDAHULUAN}

Tantangan yang dihadapi diera globalisasi yang semakin kompleks ini membuat semua pihak harus ikut pempersiapkan diri. Tantangan yang semakin terlihat ialah persaingan yang semakin ketat antar bangsa. Sehingga semua pihak harus mempersiapkan sumber daya manusia yang berkompeten. Di dunia pendidikan inilah salah satu tempat yang tepat untuk mencetak SDM berkualitas. Bukan hanya kualitas IQ tetapi kualitas moral dan etika terhadap sesama dan lingkungan juga harus terbentuk.

Lingkungan merupakan tempat kita hidup. Semua makhluk hidup bergantung kepada alam dan lingkungannya. Oleh sebab itu Pendidikan Biologi UMPalembang terdapat salah satu matakualiah wajib yaitu Pengetahuan Lingkungan. Adapun tujuan diberikan mata kuliah Pengetahuan Lingkungan salah satunya ialah agar calon sarjana yang dicetak memiliki akhlak terhadap lingkungan. Akhlak terhadap lingkungan inilah yang akan dapat membina lingkungan agar tetap terjaga keseimbangannya.

Di sekitar kita terlihat begitu kompleks masalah lingkungan yang terjadi. Tidak hanya pada kalangan orang yang tidak berpendidikan, tetapi dikalangan orang yang berpendidikan tinggi juga masih banyak terlihat. Orang cerdas terkadang tidak memikirkan lingkungan, yang mereka pikirkan hanya sebatas keuntungan belaka. Di sini peneliti ingin mecari solusi agar mahasiswa mampu memecahkan permasalahan lingkungan yang ada di sekitarnya. Sehingga dengan sendirinya mahasiswa akan terbentuk sebagai manusia yang peduli lingkungan. Oleh sebab itu peneliti menerapkan model pembelajaran Problem Based Learning atau yang sering disebut sebagai pembelajaran berbasis masalah.

Menurut Hudojo (1988) dalam (Mayasari et al. 2016)problem based learning adalah proses yang ditempuh oleh seseorang untuk menyelesaikan masalah yang dihadapinya sampai masalah itu tidak lagi menjadi masalah baginya. Kelebihan model pembelajaran problem based learning yaitu dengan metode intruksional yang menantang mahasiswa agar belajar untuk belajar bekerjasama dalam kelompok untuk mencari solusi bagi masalah yang nyata. Masalah digunakan untuk mengaitkan rasa keingintahuan, kemampuan analisis, dan inisiatif mahasiswa terhadap materi pembelajaran.

Model pembelajaran PBL merupakan cara penyajian bahan pelajaran dengan menjadikan masalah sebagai titik tolak pembahasan untuk dianalisis dan disintesis dalam usaha mencari pemecahan atau jawabannya oleh mahasiswa. Permasalahan itu dapat diajukan atau diberikan dosen kepada mahasiswa, dari mahasiswa bersama dosen, atau dari mahasiswa sendiri, yang kemudian dijadikan pembahasan dan dicari pemecahannya sebagai kegiatan-kegiatan belajar mahasiswa (Abudin, 2009 dalam (Saleh 2013)

Penerapan model pembelajaran PBL peserta didik menggrp permasalahan yang otentik dengan tujuan untuk menyusun pengetahuan mereka sendiri, mengembangkan kemampuan dalam menganalisis untuk memecahkan permasalahan dengan solusi yang tepat dan dapat mengembangkan kemandirian sehingga menumbuhkan percaya diri. PBL merupakan suatu model instruksional antara dosen dengan mahasiswa melalui pemecahan masalah berdasarkan pengalaman peserta didik itu sendiri. Peserta didik dalam PBL diberi kesempatan untuk mengembangkan kemampuannya dalam berpikir. Dosen hanya berperan fasilitator, dalam hal ini memfasilitasi konstruksi dalam mengkolaborasi pengetahuan peserta didik. Diharapkan nantinya dengan model ini peserta didik mampu menyelesaikan permasalahan yang dihadapi berdasarkan pengalamannya (Haryanti 2017).

Pembelajaran yang hanya berorientasi pada penguasaan materi memang terbukti berhasil dalam kompetisi mengingat jangka pendek, tetapi gagal dalam membekali anak memecahkan persoalan dalam kehidupan jangka panjang (Amri \& Ahmadi, 2010 dalam (Saleh 2013). Apalagi permasalahan lingkungan yang semakin komplek ini. Dalam praktik pendidikan modern, menjejali pikiran para mahasiswa dengan berbagai konsep dan teori saja tanpa disertai pengalaman di lapangan terbukti kurang efektif. Sehingga kegiatan yang dilakukan yaitu mahasiswa nantinya akan terjun langsung ke lapangan dengan melihat kondisi secara langsung permasalahan yang ada. 


\section{METODE PENELITIAN}

Penelitian ini dilaksanakan di FKIP Program Studi Pendidikan Biologi UMPalembang pada mahasiswa semester 7 . Penelitian ini merupakan penelitian Eksperimental semu. Kelas eksperimen kelas VII A yang berjumlah 44 orang mahasiswa dan kelas VII B berjumlah 35 orang mahasiswa diberikan perlakuan menggunakan Model Problem Based Learning.

Waktu pelaksanaan dilakukan pada semester ganjil TA 2018/2019 bulan SeptemberDesember 2018. Adapun data yang digunakan adalah data kuantitatif dari kedua kelas. Data kuantitatif dari kedua kelas diberikan PreetestPostest untuk mengetahui pengaruh Model Pembelajaran Problem Based learning terhadap kemampuan kognitif pada kedua kelas. Dengan memberikan soal berjumlah 22 soal dengan tipe 10 Soal Pilihan Ganda, 5 Soal Menjodohkan, 5 Soal Sebab Akibat dan 2 Soal Essay.

Dari satu kelas yang berjumlah 44 dan 38 mahasiswa dibagi menjadi 11 kelompok. Masing-masing kelompok memiliki tugas yang berbeda disesuaikan dengan topik materi sesuai RPS. Selanjutnya mahasiswa melakukan survei, identifikasi dan analisis permasalah lingkungan yang ada dengan memberikan solusi yang dirasa ideal.

\section{HASIL DAN PEMBAHASAN}

Sebelum membahas bagaimana kaitan dan pengaruh model pembelajaran PBL ini kita akan sedikit membahas sejarah singkat model PBL. Belajar dengan metode memecahkan masalah sebenarnya sudah digagas lama, bahkan ribuan tahun yang lalu. Peserta didik dapat belajar melalui serangkaian aktivitas atau proses pembelajaran yang melibatkan peserta didik secara aktif dalam menemukan jawabannya sendiri. Socratessdfvg (470 SM - 399 SM) membelajarkan murid-murinya dengan pertanyaan-pertanyaan yang mampu mengaktifkan pengetahuan tersembunyi.

Selanjutnya T.C. Chamberlin mengembangkan metode yang dikenal dengan "The Methode Of Multiple Working Hypotheses" yang dapat digunakan sebagai cara untuk memecahkan masalah pada tahun 1889 dan ada satu peneliti lagi pada tahun 1916. Selanjutnya belajar melalui pemecahan masalah dikenal di dunia pendidikan. Diantara berbagai metode pemecahan masalah yang berkembang saat itu, pembelajaran berbasis masalah yang berlabelkan Problem Based Learning (PBL) menjadi sangat terkenal di dunia pendidikan. Istilah PBL pertama kali dikenalkan oleh Don Woods berdasarkan penelitiannya dengan para mahasiswa kimia di Universitas Mc Master di Kanada pada tahun 1960an. Selanjutnya, PBL populer digunakan di seluruh dunia dan dikenal sebagai metode pembelajaran dari sekolah kesehatan Universitas Mc Master yang memiliki filosofi dasar dengan tiga visi utama (Mayasari et al. 2016).

Oleh sebab itu peneliti dapat memnfaatkan model pembelajaran yang sudah familiar ini pada mata kuliah Pengetahuan Lingkungan, sehingga diperoleh hasil penelitian berupa data nilai kognitif mahasiswa. Untuk memperoleh nilai kognitif dilakukan dua kali tes, adapun tes yang pertama dilakukan diawal perkuliahan (Pree-Test) dan tes kedua dilakukan diakhir perkuliahan (Post-Test). Soal yang diberikan berjumlah 22 soal dengan tipe 10 Soal Pilihan Ganda, 5 Soal Menjodohkan, 5 Soal Sebab Akibat dan 2 Soal Essay. Dari hasil Pree-test nilai terendah 20 dan nilai tertinggi 76 . Nilai Post-test nilai terendah adalah 66 dan tertinggi adalah 97 (Tabel 1).

Tabel 1. Data Nilai Aspek Kognitif Mahasiswa

\begin{tabular}{cccc}
\hline $\begin{array}{c}\text { Data Hasil } \\
\text { Belajar }\end{array}$ & Nilai Max & $\begin{array}{c}\text { Nilai } \\
\text { Min }\end{array}$ & $\begin{array}{c}\text { Rata- } \\
\text { rata }\end{array}$ \\
\hline Pre-test & 76 & 20 & 50,4 \\
\hline Post-test & 97 & 66 & 78,5 \\
\hline
\end{tabular}

Tabel 1 menunjukkan nilai rata-rata Pre-test sebesar 50,4 dan nilai Post-test sebesar 78,5. Selanjutnya data nilai tes yang diperoleh dimasukkan ke dalam program SPSS dan dilakukan uji t berpasangan, berikut hasil uji dapat dilihat pada Tabel 2.

Tabel 2. Hasil Uji t Pre-test, Post-test Paired Samples

\begin{tabular}{|ll|c|c|c|}
\hline & N & Sig. & Sig. \\
\hline Pair 1 & $\begin{array}{l}\text { Pree_Test \& } \\
\text { Post_Test }\end{array}$ & 44 & 0,530 & 0,530 \\
\hline
\end{tabular}


Berdasarkan Tabel 2 dapat dilihat bahwa nilai Pre-test dan Post-test memiliki nilai signifiansi sebesar 0,530 artinya sig > dari 0,05 yang berarti terdapat pengaruh yang sangat nyata di dalam penerapkan model pembelajaran PBL terhadap nilai kognitif mahasiswa yang dilihat dari nilai sebelum diberikan perlakuan dibandingkan nilai yang telah diberikan perlakuan. Hal ini senanda dengan penelitian yang telah dilakukan oleh Astutik, dkk (2019); Asiyah, dkk (2021) ratarata hasil belajar kognitif posttest siswa kelas eksperimen yang mendapatkan perlakuan model pembelajaran PBL memiliki rata-rata 80,77 dengan jumlah nilai 2100 nilai tertinggi 100 dan nilai terendah 60 sedangkan kelas kontrol yang mendapatkan perlakuan model konvensional memiliki rata-rata 70 dengan jumlah nilai 1820 nilai tertinggi 90 dan nilai terendah 50 .

Peningkatan nilai yang terjadi dari sebelum diberikan perlakuan (pembelajaran menggunakan model PBL) dan nilai setelah diberikan perlakuan (penerapan model PBL) hal ini dikarena dalam penerapan model PBL mahasiswa lebih terlatih dalam memecahkan berbagai permasalahan sesuai dengan kemampuan melalui penyelidikan secara autentik, sehingga bukan hanya saat di lapangan mahasiswa mampu memecahkan permasalahan hingga ke dalam kelas pun mahasiswa masih mengusai konsep penting yang mereka peroleh dan mereka kembangkan.

Model PBL berupaya agar mahasiswa dapat memecahkan masalah dengan berpikir lebih keras. Dalam memecahkan masalah, mahasiswa diharapkan mempunyai pemahaman konsep yang matang tentang apa yang dipelajari, fenomena apa yang terlihat dan bagaimana pemecahannya. Pengalaman belajar melalui keterlibatan langsung ke lingkungan akan membuat mereka semakin aktif dalam belajar. Keaktifan mereka sangat berpengaruh terhadap hasil belajar karena membuat mereka semakin paham tentang materi yang dipelajari, semakin menguasai konsep dan semakin pandai memecahkan suatu permasalahan yang tampak di depannya. Hal ini relevan dengan pendapat (DEWI, Sadia, and Suma 2014) bahwa pembelajaran dengan model PBL, secara kualitatif maupun kuantitatif siswa di kelas eksperimen dan kelas kontrol memiliki kemampuan berbeda dalam hal mendeskripsikan konsep fisika. Siswa di kelas eksperimen lebih baik dalam memahami dan mendeskripsikan konsep jika dibandingkan dengan kelas kontrol. Pendapat lain (Sariningsih and Purwasih 2017)mengatakan bahwa PBL membuat peserta didik memiliki rasa percaya diri tinggi setelah melakukan pembelajaran dengan model ini.

Selain itu Pembelajaran problem based learning dibentuk dengan landasan teori-teori pembelajaran yang sangat inovatif (misal konstruktivime dan pembelajaran berdasarkan pengalaman) seperti yang peneliti lakukan. Mashasiswa ke lapangan untuk menemukan masalah dan bertugas menyelesaikan dengan memberikan solusi, pengalaman berdasarkan artikel jurnal. PBL menjadi salah satu cara yang dapat digunakan oleh para dosen dalam usaha membatu mahasiswa menjadi kompeten dalam memecahkan masalah dan menghadapi tantangan ke depan. Selain itu penerapan pada mata kuliah pengetahuan lingkungan sebagai pembelajaran kedepannya agar bijak menghadapi permasalahan lingkungan. Para peneliti mengakui bahwa problem based learning dapat mengembangkan keterampilan karena PBL mampu menghubungkan antara teori dan praktek serta mengembangkan kompetensi seperti keterampilan pemecahan masalah, komunikasi, kolaborasi.

\section{KESIMPULAN}

Penelitian telah dilakukan sehingga dapat disimpulkan bahwa terdapat pengaruh yang sangat nyata di dalam penerapkan model pembelajaran PBL terhadap nilai kognitif mahasiswa yang dilihat dari nilai sebelum diberikan perlakuan dibandingkan nilai yang telah diberikan perlakuan.

\section{DAFTAR PUSTAKA}

Astuti, T. A., Nurhayati, N., Ristanto, R. H., \& Rusdi, R. (2019). Pembelajaran berbasis masalah biologi pada aspek kognitif: sebuah meta-analisis. JPBIO (Jurnal Pendidikan Biologi), 4(2), 67-74.

Asiyah, A., Topano, A., \& Walid, A. (2021). Pengaruh Problem Based Learning (PBL) Terhadap Kemampuan Pemecahan Masalah Dan Hasil Belajar Kognitif Siswa SMA Negeri 10 Kota Bengkulu. EDUKATIF: 
JURNAL ILMU PENDIDIKAN,3(3), 717727.

DEWI, P., M. Sadia, and M. Suma. 2014. "Pengaruh Model Problem Based Learning Terhadap Kemampuan Pemecahan Masalah Fisika Melalui Pengendalian Bakat Numerik Siswa Smp." Jurnal Pendidikan dan Pembelajaran IPA Indonesia 4(1).

Haryanti, Yuyun Dwi. 2017. "Model Problem Based Learning Membangun Kemampuan Berpikir Kritis Siswa Sekolah Dasar.” Jurnal Cakrawala Pendas 3(2).

Kusnandar, D. (2019). Pengaruh Model Problem Based Learning Terhadap Hasil Belajar Kognitif dan Motivasi Belajar IPA. MADRASCIENCE: Jurnal Pendidikan Islam, Sains, Sosial, dan Budaya, 1(1), 1730.

Mayasari, Tantri, Asep Kadarohman, Dadi Rusdiana, and Ida Kaniawati. 2016. "Apakah Model Pembelajaran Problem Based Learning Dan Project Based Learning Mampu Melatihkan Keterampilan Abad 21?" Jurnal Pendidikan Fisika dan Keilmuan (JPFK) 2(1): 48.

Saleh, Marhamah. 2013. "Strategi Pembelajaran Fiqh Dengan Problem-Based Learning." Jurnal Ilmiah Didaktika 14(1): 190-220.

Sariningsih, Ratna, and Ratni Purwasih. 2017. "Pembelajaran Problem Based Learning Untuk Meningkatkan Kemampuan Pemecahan Masalah Matematis Dan Self Efficacy Mahasiswa Calon Guru." JNPM (Jurnal Nasional Pendidikan Matematika) 1(1): 163. 